\title{
ОСОБЕННОСТИ ЖИЛИЩНО-БЫТОВОЙ КУЛЬТУРЫ ДОНСКИХ ШАХТЕРОВ ВО ВТОРОЙ ПОЛОВИНЕ ХІХ ВЕКА ${ }^{1}$
}

Статья посвящена малоисследованному вопросу об особенностях жилищно-бытовой культуры донских шахтеров в пореформенный период. Рассмотрен ряд вопросов, связанных с ценностями и установками шахтеров в жилищно-бытовой сфере, их запросами и жизненными стандартами.

В рассматриваемый период абсолютное большинство шахтеров Дона проживали землянках-балаганах и землянках-каютках. В ряде случаев шахтеры отказывались переселяться из землянок в благоустроенные помещения. В течение 1860-80-х годов шахтерами Дона в ходе протестных выступлений не были выдвинуты требования по улучшению жилищно-бытовых условий. Эти факты дают основание утверждать, что основная масса шахтеров отличалась непритязательностью в жилищно-бытовой сфере, готовностью мириться с бытовой неустроенностью. У части шахтеров такая бытовая непритязательность объяснялась тем, что они работали сезонно и смотрели на свое жилище при рудниках как на временное.
Вместе с тем, уже в начале пореформенного периода при рудниках Дона стали появляться полноценные дома, построенные самими шахтерами, что свидетельствует о появлении среди них прослойки рабочих с бопее высокими бытовыми потребностями и жизненными стандартами. Также, некоторые шахтеры-отходники на заработанные на рудниках деньги строили кирпичные или каменные дома в родных деревнях.

В период 1890-х годов большая часть шахтеров Дона (около 90 \%) была переселена из землянок в большие каменные казармы и дома от предприятия. Однако следует отметить, что переселение $90 \%$ шахтеров из землянок в казармы и семейные домики происходило исключительно по инициативе предприятий, что также подтверждает их бытовую непритязательность.

Ключевые слова: жилищно-бытовая культура, жизненные стандарты, непритязательность, землянки-балаганы, каютки, семейные домики, шахтеры, отходники.

\section{FEATURES OF HOUSING AND HOUSEHOLD CULTURE OF THE DON MINERS IN THE SECOND HALF OF THE XIX CENTURY}

The article is devoted to the little-studied question about the features of housing and household culture of the Don miners in the post-reform period. A number of issues related to the values and attitudes of miners in the housing sector their needs and living standards are considered.

During the period under review, the vast majority of Don miners lived in dugouts and cabins. In some cases, the miners refused to move from the dugouts to comfortable premises. During the $1860-80$-ies miners did not put forward demands for improvement of living conditions during protests. These facts give the basis to claim that the bulk of miners differed unpretentiousness in the housing and household sphere, readiness to put up with household disorder. Among some of the miners, this homely simplicity was due to the fact that they worked seasonally and looked at their home in the mines as temporary.

В советской историограффии горнорабочих Дона (и Донбасса в целом) в пореформенный период особое внимание уделялось жилищно-бытовым условиям их жизни на рудниках ([2]; [3]; [14]).
At the same time, at the beginning of the post-reform period at mines of Don the full-fledged houses constructed by miners began to appear that testifies to emergence among them a layer of workers with higher household needs and living standards. Also, some miners, hunters earned in the mines money to build brick or stone houses in their native villages.

During the 1890s, most of the Don miners (about 90\%) were relocated from dugouts to large stone barracks and houses from the enterprise. However, it should be noted that the resettlement of $90 \%$ of miners from dugouts to barracks and family houses was solely on the initiative of enterprises, which also confirms their everyday unpretentiousness.

Key words: housing and domestic culture, living standards, simplicity, dugouts-the booths, kayutki, family houses, miners, seasonal workers.

Отмечалось, что шахтеры в указанный период жили в неблагоустроенных помещениях, так как шахтовладельцы экономили на бытовом обустройстве рудничных поселков. Вместе с тем, ряд

${ }^{1}$ Статья написана в рамках исследования «Модернизация России: исследовательский опыт и образовательные практики» при финансовой поддержке гранта Южного федерального университета (ЮФУ) (проект № ВнГр-07/2017-16). 
вопросов, связанных с ценностями и установками шахтеров в жилищно-бытовой сфере, их запросами, моделями бытового поведения и жизненными стандартами в целом, остается по-прежнему малоисследованным. В этой связи актуальность приобретает вопрос об особенностях их жилищно-бытовой культуры. Источниковую базу представленного исследования составляют воспоминания современников, отчеты врачей, рапорты окружных инженеров, воспоминания самих рабочих, материалы шахтерского фольклора.

Прежде всего, следует отметить, что в пореформенный период контингент донских шахтеров формировался из малоземельных и безземельных крестьян-отходников преимущественно из губерний Центрального Черноземья. Большая часть из них проживала на рудниках в течение осенне-зимнего периода и по окончании срока найма (обычно в марте или апреле) возвращалась в родные деревни на полевые работы в собственных хозяйствах. Другие шахтеры (как правило, из безземельных крестьян) утрачивали экономические связи с родной деревней и либо селились при определенном руднике и становились оседлыми рабочими, либо постоянно переходили с одного рудника на другой и летом уходили на полевые работы к местным помещикам и кулакам [14, c. 141-148]. Первая группа численно преобладала среди горняков Дона в период 1860-80-х годов, а в период 1890-х годов, в связи с усилением аграрного перенаселения, начался рост удельного веса второй группы [14, с. 141-148].

Как следует из воспоминаний современников, отчетов врачей, рапортов окружных инженеров, в 1860-1890-х годах большинство шахтеров из крестьян-отходников проживало в больших землянках-балаганах (до 10 сажен в длину), которые строились самими артелями рабочих по договоренности с рудничной администрацией либо из выданного ею материала, либо на выделенные ей деньги. О том, как это происходило, дает представление следующий пример. Нанявшиеся в начале 1871 г. на работу на шахту Маркова артели подрядчиков Уланова и Князева, общей численностью более 30 человек, в договоре о найме «обязались устроить своими силами землянку при посредстве доставленного управляющим инженером Отто леса», «не менее 14 аршин длины» [7, л. 160 об]. Общая стоимость леса, выделенного управляющим рудником Отто этим двум артелям на строительство землянки, составила 86 рублей [7, л. 73]. Для устройства землянки рабочим также были выделены деньги: 10 рублей 92 копейки на покупку 2 столов и 10 табуретов, а также около 5 рублей на покупку металлических и деревянных тарелок и деревянных ложек [7, л. 90]. В общей сложности, постройка и обустройство этой землянки-балагана обошлось, примерно, в 100 рублей.

Обычно, после того, как артель крестьян-отходников заканчивала работу на руднике по заключенному договору и покидала рудник, такая землянка затем населялась новыми партиями прибывших на работы шахтеров. Если уже по- строенного жилья не хватало, нанявшаяся артель строила при руднике еще одну землянку-балаган. Для таких землянок, построенных самими артелями рабочих, было характерно соединение общей комнаты со спальней, столовой и кухней. Рабочие спали либо на лавках, либо, если не хватало места, на полу, либо на несъемных нарах без разделения между местами [1, с. 557].

Представление о конструкции и планировке таких построенных шахтерскими артелями больших землянок дают сведения из отчета управляющего Богообетованным рудником горнопромышленника Прохорова в Управление Горной и Соляной частями Области Войска Донского от 4 марта 1890 г Согласно этому отчету, на Богообетованном руднике имелись три новых барака-землянки размером 11,5 сажен в длину и 2 сажени в ширину и в высоту от земли до основания крыши 0,5 сажени (то есть немногим больше метра) и от земли до конька крыши 1,3 сажени (2,86 м). Также, на данном руднике имелись еще два старых балагана-землянки размером 6 сажен в длину и 2,3 сажени в ширину и в высоту от земли до основания крыши 0,5 сажени и от пола до конька крыши в 1 сажень [4, л. 15].

Схожие сведения о характере больших артельных землянок-балаганов на донских рудниках за период конца 1880-х - начала 1890-х гг. дают материалы санитарного обследования жилищ рабочих в поселках при крупных рудниках в районе Макеевки и Кальмиуса от 18 марта 1890 г [4, л. 14]. В отчете указывалось, что на всех указанных рудниках на момент осмотра все жилые помещения для рабочих представляли собой построенные самими артелями шахтеров большие землянки-балаганы, устроенные с углублением в землю от 1,5 до 2,5 аршин. В некоторых помещениях стены изнутри были оббиты досками, а в некоторых - обложены камнем на глине. Большинство помещений было без потолков. Крыша, как правило, была деревянной, из тонких досок, сверху обмазанных глиной и засыпанных землей [4, л. 14].

Также в пореформенный период часть оседлых рабочих-шахтеров проживала в самостоятельно выстроенных при рудниках небольших землянках и полуземлянках, называемых «каютками». Значительная часть таких землянок-каюток представляла собой «ямы, сверху прикрытые бревнами, иногда с небольшими световыми отверстиями» $[10$, л. 78об]. Также некоторые каютки представляли собой надземные постройки в виде сараев из тонких оштукатуренных досок. В них также не было ни полов, ни потолков [10, л. 62].

По воспоминаниям горного инженера А. М. Терпигорева, в конце 1890-х годов вокруг Сулинского рудника имелось большое шахтерское поселение, состоящее из таких землянок-каюток. Он вспоминал: «Когда же неподалеку от одного из рудников мы спустились в балку, то увидели по ее отрогам десятки небольших землянок. В них жили семейные рабочие» [18, с. 42]. «Все эти землянки строились рабочими прямо у самого склона балки или у ее отрогов, как бы врастая в них, при- 
чем три стенки этого помещения выкладывались насухо из плит песчаника, обмазывались кое-как снаружи, а иногда и изнутри, глиной, белились, а в четвертой стене были небольшая дверь и окно. Ни потолков, ни полов в такой землянке не было» [18, с. 42]. По словам рудничного врача Р. Н. Шора, каютки обычно строились из горбыля. Домики эти снаружи и внутри были обмазаны глиной, пол в них был земляной [20, с. 28-29].

Таким образом, каютки представляли собой самостоятельно построенные семейными кадровыми шахтерами из досок или камня небольшие землянки и полуземлянки без полов и потолков. Очевидно, что каютки имели большое распространение среди донских шахтеров на протяжении почти всего пореформенного периода по причине небольшой стоимости их строительства. Если постройка большой землянки-балагана обходилась не менее 80-100 рублей, то стоимость постройки небольшой землянки-каютки была, очевидно, еще меньше из-за малого их размера.

Вместе с тем, как вспоминает А. М. Терпигорев, часто шахтеры такие землянки-каютки называли «собачьими конурами», а состоящие из них поселения при рудниках - «собачьими хуторами» $[18$, с. 42]. По воспоминаниям одного из рабочих, каютки ими также часто назывались «халупами» [11, с. 155]. Таким образом, для шахтеров в рассматриваемый период было характерно двойственное отношение к землянкам-каюткам С одной стороны, они считали каютки лучшим для семейных шахтеров местом для постоянного проживания в сравнении с балаганами, а с другой не считали их полноценным жилищем, в отличие от, например, крестьянской избы или хаты.

Вместе с тем, уже в начале пореформенного периода при рудниках Дона стали появляться полноценные каменные либо деревянные дома самостоятельно построенные оседлыми шахтерами. В первую очередь появление на рудниках Дона такого рабочего жилья было связано с образованием Грушевского горного поселения при одноименном руднике. Проект создания Грушевского горного поселения был разработан в 1864 г Управлением Горной и Соляной частями Области Войска Донского с целью создания условий для формирования «класса горнорабочих». 3 октября 1864 г. было высочайше утверждено Положение о Грушевском горном поселении [8, л. 1].

По правилам этого положения, Управление горной и соляной частями «всем желающим поселиться при Грушевском руднике независимо от их сословной принадлежности выдавало ярлык с указанием выделенного на общем плане места». На оборотной стороне ярлыка были изложены обязанности «местовладельца в двухлетний срок выстроить на собственные средства каменный или деревянный фасадный дом и огородить его» $[8$, л. 1-2]. Застройка территории началась в 1867 г. [8, л. 1-2]. В 1883 г. Грушевское горное поселение было преобразовано в город Александровск-Грушевский [8, л. 1-3].

Из рапорта окружных горных инженеров в Управление Горной и Соляной частями о застройке дворовых мест от сентября 1873 г. следовало, что к этому времени на дворовых местах в Грушевском горном поселении, выданных желающим в 1870 г, уже был выстроен 61 фасадный дом, 26 фасадных домов достраивались, и на 32 выделенных местах застройка либо отсутствовала, либо (в двух случаях) имелись землянки [8, л. 31-33]. Также, по имеющимся данным, в Грушевском горном поселении в 1871 г. всем желающим под постройку так называемых «фрасадных домов» было роздано еще 79 мест [5, л. 7-8]. В 1873 г. в Грушевском горном поселении с разрешения Управления горной и соляной частями Области Войска Донского начали постройку еще 35 человек [8, л. 31-33]. Таким образом, уже в начале 1870-х годов в Грушевском горном поселении уже имелась существенная фасадная застройка. По данным, собранным комиссией А. А. Штофа, в 1900 г. «более половины» рабочих рудника РОПИТ проживали в собственных домах в городе Александровске-Грушевском [10, л. 98].

Представление о характере этих построенных самими рабочими “фасадных домиков» в Грушевском горном поселении дают следующие примеры. В 1874 г. рабочим Н. Журовым в течение двух лет был выстроен каменный фасадный двухоконный дом. В том же году шахтер Никифор Губанов построил деревянный двухоконный дом, а рабочий А. Алексеев - трехоконный каменный дом. По соседству с ними в Грушевском горном поселении размещались уже выстроенные другими шахтерами дома: трехоконный дом рабочего Тюрина, двухоконный деревянный дом рабочего Герасименко, двухоконный дом рабочего Колесникова, двухоконный дом рабочего Курятникова, трехоконный дом рабочего Дергачева, двухоконный дом рабочего Чупракова, двухоконный дом рабочего Безкурченко, двухоконный дом рабочего Деркачева [6, л. 1-2]. Как следует из планов этих домов, они представляли собой обычно однокомнатные и реже двухкомнатные помещения с сенями. У некоторых были пристройки для кухни и бани [6, л. 1-2]. В целом, по конструкции и планировке большая их часть походила на крестьянские избы или хаты. Вместе с тем, некоторые из перечисленных домов грушевских шахтеров имели более сложную планировку и состояли из нескольких комнат, что указывает на отход этой небольшой части рабочих от традиционно крестьянских стандартов жилищного строительства, на смену у них культурного образца.

Также, в 1900 г. при руднике Азовской угольной компании, по данным Комиссии А. А. Штофа, две трети рабочих проживали в своих самостоятельно выстроенных домах в хуторе Власовка [10, л. 9]. На руднике Шушпанова, по данным Комиссии Штофа, в 1900 году также имелись 83 самостоятельно выстроенных рабочими этого рудника каменных домика на войсковой земле [10, л. 101]. Эти данные подтверждает также управляющий рудником Шушпанова штейгер Е.К. Колодуб, по словам которого часть рабочих этого предприятия «живут своими домами прилично» $[13$, с. 121].

В газете Приазовский край от 3 ноября 1892 г. в статье «Рабочий вопрос на Корсунском руднике» 
сообщалось, что при основании рудника и при дальнейшем его расширении контора отводила каждому желающему из поступивших рабочих участок земли и необходимый материал под постройку дома. Рабочий сам строил себе помещение из конторского материала. Согласно установленным рудничной администрацией правилам, шахтер и его семья являлись хозяевами дома, пока он сам или его сыновья работали на руднике $[15$, с. 2]. В случае оставления рудника шахтером, дом, в котором он жил, переходил другому рабочему $[15$, с. 2]. Кроме того, каждому рабочему давалось право пасти на земле рудника две головы рогатого скота и занимать под огород 200 квадратных сажен [15, с. 2]. На Корсунском руднике, отмечал автор статьи в 1892 году, «теперь имеется 250 таких отдельных домиков» [15, с. 2].

Постройка собственного деревянного, кирпичного или каменного дома должна была, как свидетельствуют воспоминания современников, составить не менее 120 рублей. Заработная плата холостых квалифицированных рабочих в конце XIX века обычно не превышала 30-40 рублей в месяц [10, л. 74-78]. У семейного шахтера, при условии, что его жена и дети старше семи лет также работали, получая от 5 до 9 рублей в месяц [12, с. 98], совокупный месячный доход, таким образом, мог превышать 50 рублей. При этом, месячные расходы холостого рабочего должны были составить не менее 15 рублей, а семейного - от 25 до 36 рублей [17, с. 180-181]. Следовательно, построить собственный дом холостой или семейный шахтер мог только в двух случаях: либо накопив за несколько лет работы нужную сумму, либо получив строительный материал от рудничной администрации (как в долг, так и бесплатно).

Приведенные выше примеры постройки шахтерами собственных домов доказывают, что такое решение жилищной проблемы самими рабочими было возможно, но этим путем шло очень мало рабочих. Основная масса артельных и семейных рабочих предпочитала жить в описанных выше артельных балаганах и в недорогих в постройке небольших каютках. В этой связи особый интерес представляют воспоминания горнопромышленника А. А. Ауэрбаха, относящиеся к середине 1870-х г. Он сообщает, что, когда им были выстроены взамен землянок казармы и семейные домики, рабочие, к его удивлению, «решительно отказались переходить из землянок в казармы». Один из шахтеров объяснял А. Ауэрбаху: «привыкли мы жить свиньями, так нам и землянка не противна, поживешь у вас в хоромах, каких ни на одном другом руднике нет, от грязи и смраду отвыкнешь, так и тяжело будет опять в землянку попасть, если вы уволите, а так как мы народ такой, что сегодня здесь, а завтра Бог знает где, то лучше и не привыкать к хорошему помещению» [1, с. 557]. Как отмечал П. И. Фомин, что «для шахтеров была свойственна привычка к плохим условиям жизни» $[19$, с. 350]. Утверждение подтверждают материалы рабочего движения, согласно которым, в течение 1860-80-х годов шахтеры как
Дона, так и Донбасса в целом, в ходе протестных выступлений не выдвинули ни одного требования по улучшению жилищно-бытовых условий [14, c. 178-249]

Во многом это было связано с тем, что на свое пребывание на рудниках значительная часть шахтеров, основную массу которых составляли малоземельные и безземельные крестьяне-отходники из центрально-черноземных губерний, смотрели как на временное и мечтали со временем покинуть их и вернуться в родную деревню. Об этом свидетельствуют следующие данные. Так, по воспоминаниям шахтера-отходника из тамбовского села Вирятино Г. П. Дьякова, в семье его деда большая часть заработанных его сыновьями на шахтах денег откладывалась на строительство кирпичных домов. После шести лет работы на шахтах ими было построено четыре кирпичных дома [16, с. 44-54]. Так, в 1895 году один из Дьяковых на заработанные на руднике деньги построил однокомнатный кирпичный дом площадью 45 квадратных метров [16, с. 44-54]. В 1897 году еще один из братьев Дьяковых, также на заработанные на руднике деньги, построил кирпичный дом, а в 1903 году он пристроил к нему большие кирпичные сени [16, с. 44-54]. В 1898 году его родственник, шахтер-отходник Е. А. Дьяков, построил кирпичный дом, состоящий из горницы и кухни. Для строительства дома им было куплено 19000 кирпичей на 95 рублей. Оплата труда каменщиков за 10 дней работы составила 25 рублей. В целом, постройка кирпичного дома Е. А. Дьякова обошлась ему в 120 рублей [16, с. 44-54]. Также, на заработанные в Донбассе деньги еще один шахтер-отходник из села Вирятино, Митрофран Матрохин, в 1890-е годы построил двухкомнатный кирпичный дом площадью в 66 квадратных метра, а в 1903 году он пристроил к горнице кирпичную кухню и кирпичные сени и перенес русскую печь в кухню, а в горнице установил голландскую печь [16, с. 44-54]. Примечательно, что первые кирпичные дома строились вирятинскими шахтерами-отходниками по плану срубных изб и состояли из одной жилой комнаты с сенями. Получалась «кирпичная изба». Однако, в 1890-е годы, под влиянием отхода на шахты, постепенно изменялись требования некоторых крестьян-отХодников к своему жилищу. С заменой деревянных жилищ кирпичными менялась и их внутренняя планировка и обстановка. Как видно из приведенных выше примеров, происходило разделение кухни и горницы. Горница для крестьян-отходников становилась символом достатка [16, с. 44-54]. Таким образом, для части работавших шахтерами на рудниках Дона крестьян-отходников было характерна смена культурного образца жилища, выразившаяся в переходе от однокомнатной избы с сенями к дому, состоящему из нескольких комнат.

В целом, в конце XIX - начале XX в. в Вирятине местными кулаками и шахтерами-отходниками было построено в общей сложности 230 кирпичных домов [16, с. 44-54]. При этом следует отметить, что, по данным того же источника, и в этот период большая часть шахтеров-отходников из 
села Вирятино по-прежнему проживала в небольших крестьянских избах и хатах [16, с. 44-54].

В целом, представленные данные свидетельствуют о том, что лишь небольшая часть шахтеров, как оседлых, так и сезонников, имела стремление к улучшению своего жилища при рудниках собственными силами. Основная же масса как тех, так и других, проявляла бытовую непритязательность, готовность жить в землянках, каютках и балаганах.

В период промышленного подъема 1890-х гг углепромышленниками Дона было начато строительство для шахтеров казарм и семейных домов, имевшее своей целью формирование при рудниках контингента постоянных рабочих

Представление об условиях жизни в построенных в это время казармах дают материалы Комиссии члена Горного совета А. А. Штофа, обследовавшей положение рабочих Донбасса в 1900 году. Из этих материалов следует, что некоторые казармы были хорошо обустроены, имели полы и потолки, отдельные столовые и кухни. Так, по заключению Комиссии А. А. Штофа, сравнительно хорошо были обустроены казармы при руднике РОПИТ. Это были двухэтажные каменные казармы. В центре каждой из них располагались кухня, плита и сушилка для одежды. Полы в них были деревянными. Нары для рабочих были разгорожены [10, л. 98 - 980б]. Благоустроенностью отличались также некоторые казармы на Кальмиус-Богодуховском руднике Алексеевского общества $[10$, л. $98-980 б]$.

Однако, подавляющее большинство казарм по мнению членов комиссии Штофра, по своей конструкции более напоминали сараи. Так, при руднике Панченко, по данным Комиссии А. А. Штофа, в 1900 году имелось 8 казарм типа сараев из камня, без потолка и пола [10, л. 76 76об]. Так, треть рабочих Азовской угольной компании в 1900 году проживала в каменных казармах без потолка и пола. Отдельной столовой и кухни в этих казармах не было [10, л. 99]. При Рыковском руднике Общества Рыковских копей в 1900 году имелись 4 каменные казармы с земляными полами и без специальных помещений для кухни и столовой $[10$, л. 75].

По данным Статистического Бюро Совета Съездов горнопромышленников Юга России в 1901 году в казармах проживало 52,4 \% всех шахтеров Донбасса [14, с. 148-149]. Между тем шахтеры отрицательно относились к казармам и называли их «пересыльными тюрьмами» [11 c. 149]. Как признавали сами семейные шахтеры им из-за постоянных ссор и драк между холостыми шахтерами им не нравилось жить в этих казармах и они предпочли бы жить в собственной землянке [10, л. 93]. Один рабочий отмечал, что в сравнении с казармой землянка считается «настоящей квартирой» $[10$, л. 75$]$.

Помимо казарм в период 1890-х годов предприятия развернули строительство для оседлых кадровых рабочих так называемых «семейных домиков». Как и казармы, семейные домики для шахтеров строились предприятиями по плану специально нанятыми рабочими-строителями.
Представление об устройстве и условиях жизни в семейных домиках дают материалы, собранные в апреле 1900 года Комиссией А. А. Штофра. Согласно данным этого источника, в 1900 году на Кальмиус-Богодуховском руднике Алексеевского горнопромышленного общества имелся 71 четырехквартирный каменный дом для семейных рабочих. Квартира для семейного рабочего в каждом из таких домов состояла из одной комнаты и сеней и имела деревянный потолок и глинобитный пол [10, л. 76 - 76об]. В 1898 г. на руднике Общества Чулковского рудника для 300 рабочих данного предприятия рудничной администрацией было выстроено 136 семейных домиков. Согласно содержащему эти сведения отчету управляющего Чулковским рудником, больше половины указанных семейных домиков состояли из двух комнат и имели отдельное помещение для кухни $[10$, л. 31]. Также в 1900 году в поселке при Чулковском руднике для семейных рабочих были выстроены так называемые «лимпачевые домики» с глиняными полами и потолками. Каждый домик состоял из одной комнаты с сенями и погребом во дворе [10, л. 31]. При Кальмиусском руднике Общества Рыковских копей в 1900 г. имелись 8 четырехквартирных домиков, занятых мастеровыми. Каждая квартира в этих домиках состояла из двух комнат. Полы в этих домах были глиняными [10, л. 78]. При шахте №3 Макарьевского рудника Общества Рыковских копей имелись 2 каменных одноквартирных домика для рабочих. Квартира в каждом из них состояла из одной комнаты в 9 кубических сажен и сеней. Полы в комнатах были глиняными, имелись потолки [10, л. 82]. Для «привилегированных рабочих" на Берестово-Богодуховском руднике Голубовского Берестово-Богдуховского товарищества в 1900 году имелись 12 двухквартирных домиков для 24 семейных рабочих. Каждая квартира состояла из комнаты в 7 кубических сажен с земляными и глиняными полами и потолками [10, л. 84]. При руднике РОПИТ, по данным Комиссии А. А. Штофра, в 1900 г. имелись семейные многоквартирные каменные дома на 331 рабочего [10, л. 98]. В комнатах были деревянные полы и обмазанные глиной потолки [10, л. 98 - 98об]. На руднике Шушпанова, по данным Комиссии Штофа, в 1900 г. имелись 2 каменных дома, разделенных на квартиры для семейных по 2 комнаты с отдельной кухней [10, л. 101об].

Условия жизни в «семейных домиках» были существенно лучше, чем в землянках и казармах, что объективно способствовало формированию у шахтеров новых черт материально-бытовой культуры, прививало им более высокие стандарты жизни В целом, в 1900 г, согласно данным Статистического Бюро Совета съездов горнопромышленников Юга России, в семейных домиках проживало уже 38,5 \% всех шахтеров Донбасса [14, с. 148].

Однако следует отметить, что переселение 90 \% шахтеров из землянок в казармы и семейные домики происходило исключительно по инициативе предприятий. Поэтому и после масштабного строительства предприятиями в период 1890-х гг казарм и семейных домиков на многих рудниках 
сохранялись землянки-балаганы и каютки. Так, из описи жилых помещений для рабочих на рудниках «Анонимного общества Прохоровских копей на Донце» от 26 октября 1898 г. следует, что на них было 32 балагана "в земле», занятых большим количеством рабочих, в том числе и семейных [9, л. 6].

В начале XX века на Макеевском руднике Русско-Донецкого общества, по данным Комиссии A. А. Штофра, в 1900 г. при шахте «София» по-прежнему оставались 17 самостоятельно выстроенных семейными рабочими землянок-каюток без полов и потолков, с засыпанной землей крышей $[10$, л. 80]. На шахте «Капитальной» Русско-Донецкого общества в 1900 году имелось 20 таких землянок-каюток [10, л. 80]. На Евдокиевском руднике Кошкина в 1900 г имелись самостоятельно выстроенные семейными шахтерами большие каюты-полуземлянки без полов и потолков, а также несколько небольших землянок [8, л. 80]. Сохранялись землянки-каютки в 1900 г., по данным Комиссии А. А. Штофа, и при руднике Азовской угольной компании, а также при руднике Панченко и при других грушевских рудниках $[10$, л. 9]. На Берестово-Богодуховском руднике в 1900 г. имелись 41 землянка-каютка на 41 шахтерскую семью. Кроме этих землянок, как отмечается в дневнике Комиссии А. А. Штофра, в одной из балок при том же руднике имелась также группа из 30 землянок, называемая самими рабочими «собачьим хутором». Эти землянки представляли собой ямы, сверху прикрытые бревнами, иногда с небольшими световыми отверстиями [10, л. 87].

Таким образом, в период 1860-80-х гг. абсолютное большинство шахтеров Дона проживали в наспех устроенных ими самими по договоренности с рудничной администрацией больших и плохо обустроенных землянках-балаганах и каютках. В ряде случаев, как отмечали современники, шахтеры отказывались переселяться из землянок в благоустроенные помещения. Также, как свидетельствуют материалы рабочего движения, в течение 1860-80-х п. шахтерами как Дона, так и Донбасса в целом в ходе протестных выступлений не были выдвинуты требования по улучшению жилищно-бытовых условий. Эти факты дают основание утверждать, что основная масса шахтеров отличалась непритязательностью в жилищно-бытовой сфрере, готовностью жить в землянках, балаганах и каютках, которые они сами не считали полноценным жилищем, и мириться с бытовой неустроенностью.
У части шахтеров такая бытовая непритязательность объяснялась тем, что они работали сезонно и сохраняли связь с деревней, а потому смотрели на свое жилье при рудниках как на временное. В силу этого они были готовы терпеть временные бытовые трудности и не проявляли стремления к улучшению своего жилища за собственный счет. Это подтверждает тот факт, что некоторые шахтеры-отходники на заработанные на рудниках деньги строили кирпичные или каменные дома в родных деревнях, в то время как на рудниках они жили в неблагоустроенных землянках.

Вместе с тем, уже в начале пореформенного периода при рудниках Дона стали появляться полноценные каменные либо деревянные дома, построенные самими шахтерами, что свидетельствует о появлении среди них прослойки рабочих с более высокими бытовыми потребностями и жизненными стандартами.

В период промышленного подьема 1890-х гг в рудничных поселках Области Войска Донского большая часть шахтеров (около 90 \%) была переселена из землянок в большие каменные казармы с полами и потолками и в одноквартирные и многоквартирные каменные дома от предприятия. Условия жизни в “семейных домиках» были существенно лучше, чем в землянках и казармах, что объективно способствовало формированию у проживавших в них шахтеров новых черт материально-бытовой культуры, прививало им более высокие стандарты жизни. Однако следует отметить, что переселение 90 \% шахтеров из землянок в казармы и семейные домики происходило исключительно по инициативе предприятий. Поэтому и после масштабного строительства предприятиями в период 1890-х годов казарм и семейных домиков на многих рудниках сохранялись землянки-балаганы и каютки и проживавшие в них артельные и семейные шахтеры (около $10 \%$ от их общего состава) не проявляли инициативы по постройке собственного качественного жилья в отличии от своих немногочисленных товарищей, построивших собственные дома.

В целом, представленные данные свидетельствуют о том, что лишь небольшая часть шахтеров, как оседлых, так и сезонников, имела стремление к улучшению своего жилища собственными силами. Основная же масса как тех, так и других, проявляла бытовую непритязательность, готовность жить в землянках на рудниках и тесных избах в родной деревне.

\section{Источники и литература}

1. Ауэрбах А. А. Воспоминания о начале развития каменноугольной промышленности в России // Русская старина 1909. Сентябрь. С. 544-566.

2. Бакулев Г. Д. Развитие угольной промышленности Донецкого бассейна. М.: Госполитиздат, 1955. 672 с.

3. Гессен Ю. И. История горнорабочих СССР. В 2-х томах. Т. 2. М.: Изд. ЦК Союза горнорабочих, 1929. 294 с.

4. Государственный архив Ростовской области (далее - ГАРО). Ф. 32. Оп. 1. Д. 581.

5. ГАРО. Ф. 32. ОП. 1. Д. 963.

6. ГАРО. Ф. 32. ОП. 1. Д. 590

7. ГАРО. Ф. 32. Oก. 2. Д. 680

8. ГАРО. Ф. 32. Оп. 2. Д. 1017.

9. ГАРО. Ф. 32. Оп. 2. Д.1178 
10. ГАРО.Ф. 455. ОП. 3. Д. 282

11. Ионов А. И. Песни и сказы Донбасса. Сталино: Донбасс, 1960. 345 с.

12. Историко-бытовые экспедиции. 1951-1953 гг. Материалы по истории пролетариата и крестьянства России конца XIX - начала XX века. Под общей редакцией академика А. М. Панкратовой. М.: Госкультпросветиздат, 1955. 222 с.

13. Колодуб Е. К. Труд и жизнь горнорабочих грушевских антрацитовых рудников. М.: Тип. И.Я. Полякова, 1905. $127 \mathrm{c}$

14. Потолов С. И. Рабочие Донбасса в XIX веке. М.-Л.: Изд-во Академии Наук СССР, 1963. 254 с

15. Приазовский край. 1892. 3 октября.

16. Село Вирятино в прошлом и настоящем. Опыт этнографического изучения русской колхозной деревни / отв. ред. П. И. Кушнер. М.: Изд-во Академии Наук СССР, 1958. 279 с.

17. Серый Ю. И. Рабочие Юга России в период империализма. Ростов-на-Дону: Изд-во Ростовского государственного университета. 1971. 211 с.

18. Терпигорев А. М. Воспоминания инженера. М.: Изд-во Академии Наук СССР, 1956. 272 с.

19. Фомин П. И. Горная и горнозаводская промышленность Южной России. Т. 1. Харыков: Типография Б. Бенгис 1915. $487 \mathrm{c}$

20. Шор Р. Н. Шахтеры. СПб: Новый мир, 1906. 32 с.

\section{References}

1. Auerbach A. A. Vospominaniya o nachale razvitiya kamennougolnoy promyshlennosty $\vee$ Rossii (Memories of the beginning of the development of coal industry in Russia) // Russkaya starina. 1909. September. P. 544-566. (In Russian)

2. Bakulev G. D. Razvitie ugolnoi promyshlennosti Donetzkogo basseyna (Development of coal industry of Donetsk basin). M.: Gospolitizdat, 1955. 672 p.

3. Gessen Yu. I. Istoriya gornorabochih SSSR (History of miners of the USSR). In two volumes. Vol. 1. Moscow, 1929. 294 p (In Russian)

4. State Archive of Rostov Region (GARO). F. 32. Inv. 1. D. 581. (In Russian)

5. State Archive of Rostov Region (GARO). F. 32. Inv. 1. D. 963. (In Russian)

6. State Archive of Rostov Region (GARO). F. 32. Inv. 1. D. 590. (In Russian)

7. State Archive of Rostov Region (GARO). F. 32. Inv. 2. D. 680 . (In Russian)

8. State Archive of Rostov Region (GARO). F. 32. Inv. 2. D. 1017. (In Russian)

9. State Archive of Rostov Region (GARO). F. 32. Inv. 2. D. 1178. (In Russian)

10. State Archive of Rostov Region (GARO). F. 455. Inv. 2. D. 282. (In Russian)

11. Ionov A. I. Pesni i skazy Donbassa (Songs and stories of Donbass). Stalino: Donbass Press, 1960.345 p. (In Russian)

12. Istoriko-Bytovye Expedicii 1951-1953 godov. Materialy po istorii proletariat i krestyanstva $\mathrm{V}$ Rossii $\mathrm{V}$ konce XIX nachale XX vekov (Historical and Household expedition 1951-1953. Materials on the history of the proletariat and the peasantry of Russia in the late XIX - early XX century) / ed by A.M. Pankratova. Moscow: Goskultprosvetizdat publ., 1955. 222 p. (In Russian)

13. Kolodub E. K. Trud i ghizn gornorabochih na grushevskih antracitovyh rudnikah (Work and life of miners of Grushevsky anthracite mines). Moscow, 1905. 127 p. (In Russian)

14. Potolov S. I. Rabochie Donbassa v XIX veke (Workers of the Donbass in the XIX century). Moscow - Leningrad, 1963 254 p. (In Russian)

15. Priazovskiy kray. 1892. October 10. (In Russian)

16. Selo Viryatino v proshlom I nastoyashem. Opyt izucheniya russkoi kolhoznoi derevni (The village of Viryatino in the past and present. Experience of ethnographic study of the Russian collective farm village) / ed by $\mathrm{P}$. I. Kushner. Moscow: Publishing house of the USSR Academy of Sciences, 1958. 279 p. (In Russian)

17. Seryi Y. I. Rabochie Yuga Rossii v period imperializma (Workers of the South of Russia in the period of imperialism). Rostov - on - Don: Publishing House of Rostov State University, 1971. 211 p. (In Russian)

18. Terpigorev A. M. Vospominaniya gornogo ingenera (Memoirs of a mining engineer). Moscow: Publishing house of the USSR Academy of Sciences. 1956. 272 p. (In Russian)

19. Fomin P. I. Gornaya I gornozavodskaya promyshlennost Yughnoi Rossii (Mining and mining industry of southern Russia). Vol. 1. Kharkov: The Printing House B. Bengis, 1915. 487 p. (In Russian)

20. Shor R. N. Shahtery (Miners). St.Petersburg: Noviy mir publ., 1906. 32 p. (In Russian)

\section{Сведения об авторе}

Мануковский Николай Георгиевич - младший научный сотрудник кафедры отечественной истории средних веков и раннего нового времени института истории и международных отношений Южного федерального университета (Ростов-на-Дону) / manuckovsckij. nikolai@yandex.ru

\section{Information about the author}

Manukovskiy Nikolay - junior researcher, Chair of national history of the middle ages and early modern times, Institute of history and international relations, Southern Federal University (Rostov-on-Don) / manuckovsckij.nikolai @yandex.ru 